\title{
Preliminary Study of the Rheological and Mechanical Properties of Alkali-activated Concrete Based on Tungsten Mining Waste Mud
}

\section{Abdellhakim Benhamouda and João Castro-Gomes}

Centre of Materials and Building Technologies (C-MADE/UBI), Department of Civil Engineering and Architecture, University of Beira Interior (UBI), 6201-001 Covilhã, Portugal

\section{Abstract}

The rheological properties of Portland cement (PC) concrete have been extensively studied and compared with those of alkali-activated concrete (AAC). This study discusses the effect of the liquid to solid ratio on the rheological and mechanical properties of AAM concrete, based on mining waste mud as the binder phase, and compares them with those of Portland cement concrete (PCC). The AAM concrete studied is a mix of coarse aggregate 6/15, two types of sand (finer and coarse sand),

Corresponding Author: Abdelhakim Benhamouda benhamouda.abdelhakim@gmail .com

Received: 20 March 2020 Accepted: 30 April 2020 Published: 13 April 2020

Publishing services provided by Knowledge E

(c) Abdelhakim Benhamouda and João Castro-Gomes. This article is distributed under the terms of the Creative Commons Attribution License, which permits unrestricted use and redistribution provided that the original author and source are credited.

Selection and Peer-review under the responsibility of the RICON19 - REMINE International Conference Conference Committee.

\section{G OPEN ACCESS} and a precursor. The precursor is a mix of $70 \%$ tungsten mining waste mud, $15 \%$ waste glass and $15 \%$ metakaolin. This mix was activated by a combination of sodium hydroxide $(\mathrm{NaOH})$ and sodium silicate $\left(\mathrm{Na}_{2} \mathrm{SiO}_{3}\right)$ and the PCC was a mix of the same aggregate but with cement as binder and water as a liquid. The activator/precursor ratio was studied $0.5,0.52,0.54,0.56$ and 0.58 . The results obtained show a similar rheological behaviour between $\mathrm{AAC}$ and $\mathrm{PCC}$, the workability affected by L/S increases with the increasing ratio $L / S$ in $A A C$ and for $L / S=0.5$ slump was $6 \mathrm{~cm}$ and was $16 \mathrm{~cm}$ for $\mathrm{L} / \mathrm{S}=0.58$. Regarding the mechanical properties, the results obtained in 7 days showed similar performance in AAC and PCC. The compressive strength also decreases with the increasing of $\mathrm{L} / \mathrm{S}$, in $\mathrm{AAC}$ with $\mathrm{L} / \mathrm{S}=0.5$ the compressive strength was $15.9 \mathrm{MPa}$ and for $L / S=0.58$ was 10.5 .

Keywords: Tungsten mining waste, Rheology, Mechanical properties, Portland cement, alkali-activated concrete

\section{Introduction}

Currently, the construction industry is facing a great challenge: the protection of the environment and the usage of waste and recycled materials [1]. The Portland cement (PC) production is a factor responsible for $\mathrm{CO}_{2}$ greenhouse gases emissions between $6 \%$ and $8 \%[2]$.

Besides, in Europe, there is a major concern on the quantity and diversity of hazardous solid waste production. 
The increasing concern about the environmental consequences of waste disposal has led to a new investigation on new utilization (reuse) possibilities. For example, large quantities of sludge and by-products such as fly ash are produced during the combustion of coal used for electricity generation [3]. Also, in Europe, mining and quarrying industry waste is very relevant. These activities produce about $55 \%$ of total industrial wastes according to recent Eurostat data [4].

Alkali-activated concretes are considered to be revolutionary materials that in the foreseeable future may replace, in some applications, the Portland cement (OPC)-based concrete [5-7].

In the alkali activation process, the geopolymerization reaction primarily involves the chemical reaction between the dissolved species of silicates and aluminates in the presence of a highly alkaline environment. The presence of water in the alkaliactivated system merely acts as a transport medium between the dissolved silicates and aluminates ions. Besides, mixing water also provides workability to the freshly mixed alkali-activated concretes, as it does not participate directly in the alkali-activation reaction [8]

The physical and chemical properties of AAC depend largely on the raw materials used and on the curing conditions.

The chemical activator or alkali activator solution plays a vital role in the initiation of the geopolymerization process. Generally, a strong alkaline medium is necessary to increase the surface hydrolysis of the aluminosilicate particles present in the raw material while the concentration of the chemical activator has a pronounced effect on the mechanical properties of the geopolymers $[9,10]$.

For a better understanding of the behavior and performance of alkali-activated (AA) materials, it is important to study their rheological and mechanical properties for the manufacturing of AA-based products.

Rheology is the study of the fluidity and deformation of matter in a fresh or hardness state, and the emphasis on flow means that it is concerned with the relationships between stress, strain, rate of strain, and time [11].

The aim of this study is to produce an alkali-activated concrete using a conventional method as PCC. Different ratio of liquid/solid was fixed to study the rheological and mechanical properties of this concrete and compare it to Portland cement concrete.

\section{Materials and Methods}




\subsection{Materials}

To prepare AA concrete, we used, as a precursor (P), Metakaolin (Mk), tungsten mining waste mud (TMWM) and waste glass (WG). The metakaolin was supplied by BASF with the reference name "MASTERLIFE Mk", mud waste was collected from Panasqueira tungsten mine, located in Covilhã-Portugal and the waste glass was obtained by crushing glass bottles. The chemical composition (determined by SEM-EDX) and the physical properties (bulk density and Blaine finesses) are presented in Table.1

TABLE 1: Chemical composition and physical properties of (Mk), (TMWM), (WG) and (PC) in \%.

Chemical composition
$\mathrm{Na}_{2} \mathrm{O}$
$\mathrm{SiO}_{2}$
$\mathrm{Al}_{2} \mathrm{O}_{3}$
$\mathrm{~K}_{2} \mathrm{O}$
$\mathrm{CaO}$
$\mathrm{SO}_{3}$
$\mathrm{Fe}_{2} \mathrm{O}_{3}$
$\mathrm{MgO}$
Bulk density $\left(\mathrm{g} / \mathrm{cm}^{3}\right)$
Blaine fineness $\left(\mathrm{cm}^{2} / \mathrm{g}\right)$

\begin{tabular}{|c|}
\hline Mud waste \\
\hline 0.85 \\
\hline 46.67 \\
\hline 17.01 \\
\hline 4.90 \\
\hline 0.69 \\
\hline 7.90 \\
\hline 15.47 \\
\hline 4.83 \\
\hline 3.10 \\
\hline 1835
\end{tabular}

\begin{tabular}{|c|}
\hline Waste Glass \\
\hline 12.52 \\
\hline 68.13 \\
\hline 2.80 \\
0.86 \\
\hline 10.52 \\
\hline 0.23 \\
\hline 2.90 \\
2.04 \\
\hline 2.49 \\
\hline 2665
\end{tabular}

\begin{tabular}{|c|}
\hline Meta kaolin \\
\hline 0.32 \\
\hline 52.28 \\
\hline 42.99 \\
\hline 0.94 \\
\hline$/$ \\
\hline$/$ \\
\hline 1.49 \\
\hline 0.47 \\
\hline 0.2683 \\
\hline 4467
\end{tabular}

\begin{tabular}{|c|}
\hline Portland cement \\
\hline 0.09 \\
\hline 10.02 \\
\hline 2.62 \\
\hline 1.83 \\
\hline 76.79 \\
\hline 5.03 \\
\hline 2.49 \\
1.05 \\
\hline 3.15 \\
\hline 3860
\end{tabular}

The liquids used in this formulation were sodium hydroxide (SH) $\mathrm{NaOH}$, sodium silicate (SS) $\mathrm{Na}_{2} \mathrm{SiO}_{3}$ and potable water. Sodium hydroxide solution was prepared by dissolving sodium hydroxide pellets (98\% purity obtained from Fisher Scientific, Schwerte, Germany). Sodium silicate was obtained from Solvay SA, Póvoa de Santa Iria, Portugal. Table. 2 shows the chemical composition and density of activators.

TABLE 2: Chemical composition and density of (SH) and (SS) in \% by weight.

Chemical composition
$\mathrm{Na}_{2} \mathrm{O}$
$\mathrm{SiO}_{2}$
$\mathrm{Al}_{2} \mathrm{O}_{3}$
$\mathrm{H}_{2} \mathrm{O}$
Density $\left(\mathbf{g} / \mathrm{cm}^{3}\right)$

\begin{tabular}{|c|}
\hline Sodium hydroxide \\
\hline 13.02 \\
0.00 \\
0.00 \\
43.27 \\
1.0192 \\
\hline
\end{tabular}

\begin{tabular}{|c|} 
Sodium silicate \\
\hline 19.37 \\
\hline 62.60 \\
\hline 0.90 \\
\hline 142.32 \\
\hline 1.5725 \\
\hline
\end{tabular}

Three types of aggregate were used in this study: finer sand, coarse sand and coarse aggregate. 
Sieve analyses were performed to determine the particle size distribution. Fig.1 shows the particle size distribution of the aggregate used in this study.

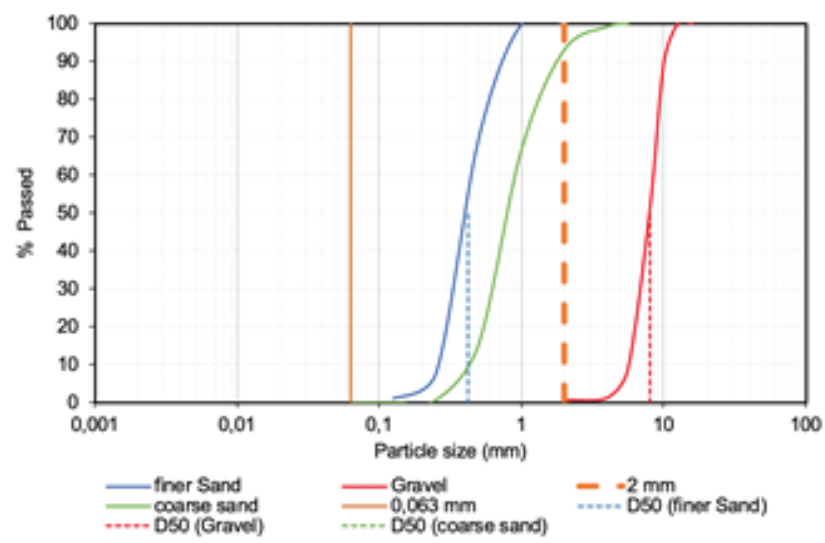

Figure 1: Particle size distribution of the aggregate used in this study.

\subsection{Methods}

\subsubsection{Mix design}

The alkali activated concrete (AAC) was prepared using a conventional method as in PCC, since the density of $A C C$ and PCC is almost equal $\left(2400 \mathrm{~kg} / \mathrm{m}^{3}\right)$ using the previous result obtained in AA paste with the same mix ( $70 \%$ mud waste, $15 \%$ of waste glass and 15\% of metakaolin) Fig.2.

Table. 3 presents a sequence of steps to determine the mix proportion to produce AAC. The precursor was a mix of $70 \%$ mud waste, $15 \%$ waste glass and $15 \%$ metakaolin. The activator (A) was a mix of $80 \%$ sodium silicate and $20 \%$ sodium hydroxide. The aggregate was finer sand (F.S) with finesse module 2.01, coarse sand (C.S) with a finesse of 3.2 and coarse aggregate (C.A) with a maximum diameter of $12.5 \mathrm{~mm}$.

After determining the mix proportion following the previous steps, 5 ratios L/S in AAC and PCC were studied L/S $(0.5,0.52,0.54,0.56$ and 0.58$)$ in AAC and PCC as shown in Fig.3.

The Mixture proportions used in this study are detailed in the Table.4.

\subsubsection{Slump}

The concrete workability was determined with a slump test on the samples. The slump cone has an upper diameter of $20 \mathrm{~cm}$, a lower diameter of $10 \mathrm{~cm}$, and height of 30 


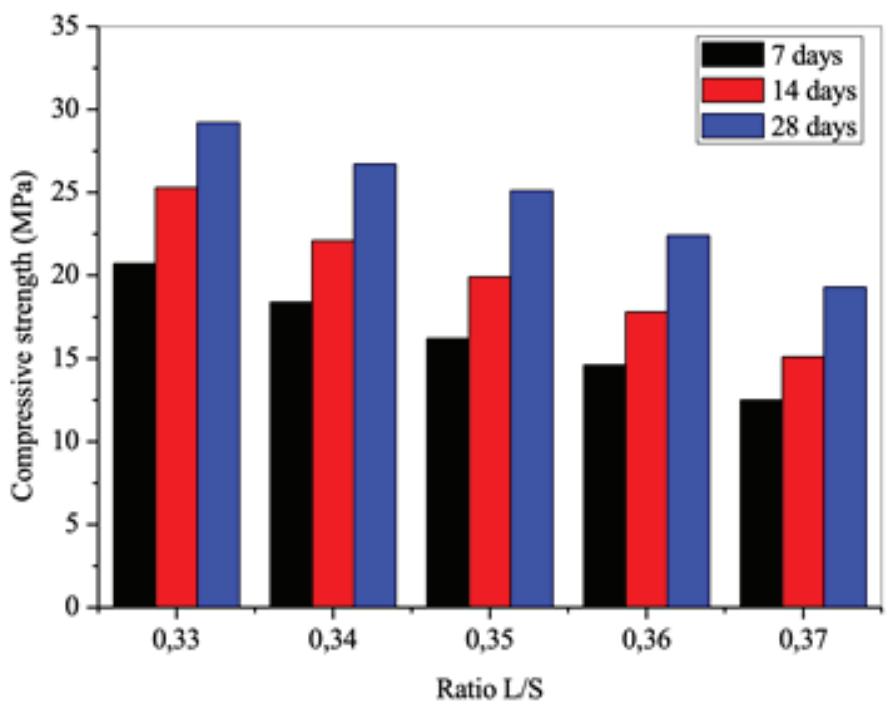

Figure 2: Compressive strength as function of a/p ratio.

TABLE 3: Steps to determine the mix proportion

\begin{tabular}{l|l} 
Step1 & Select the amount of precursor \\
Step2 & Select the ratio L/S $(0.5,0.52,0.54,0.56$ and 0.58) \\
Step 3 & Determine the amount of activator \\
Step 4 & Calculate the amount of water required \\
Step 5 & Calculate the volume of paste and aggregate \\
Step 6 & Calculate the content of fine and coarse aggregate \\
Step 7 & Adjust due to humidity and water absorption \\
Step 8 & Mix proportion
\end{tabular}

TABLE 4: Mix proportion for $1 \mathrm{~m}^{3}$

\begin{tabular}{|l|l|l|l|l|l|l|} 
Mixes & C.A (Kg) & C.S $(\mathbf{K g})$ & $\mathbf{F . S}(\mathbf{K g})$ & $\mathbf{P}(\mathbf{K g})$ & $\mathbf{W}(\mathbf{K g})$ & $\mathbf{A}(\mathbf{K g})$ \\
\hline PCC1 & 930 & 533.4 & 228.6 & 400 & 200 & $/$ \\
\hline PCC2 & 930 & 533.4 & 228.6 & 400 & 208 & $/$ \\
\hline PCC3 & 930 & 533.4 & 228.6 & 400 & 216 & $/$ \\
\hline PCC4 & 930 & 533.4 & 228.6 & 400 & 224 & $/$ \\
\hline PCC5 & 930 & 533.4 & 228.6 & 400 & 232 & $/$ \\
\hline AAC1 & 930 & 533.4 & 228.6 & 400 & 25 & 200 \\
\hline AAC2 & 930 & 533.4 & 228.6 & 400 & 25 & 208 \\
\hline AAC3 & 930 & 533.4 & 228.6 & 400 & 25 & 216 \\
\hline AAC4 & 930 & 533.4 & 228.6 & 400 & 25 & 224 \\
\hline AAC5 & 930 & 533.4 & 228.6 & 400 & 25 & 232 \\
\hline & & & & & &
\end{tabular}

$\mathrm{cm}$. The cone is positioned in the center of the plate. After that the mould is filled with 


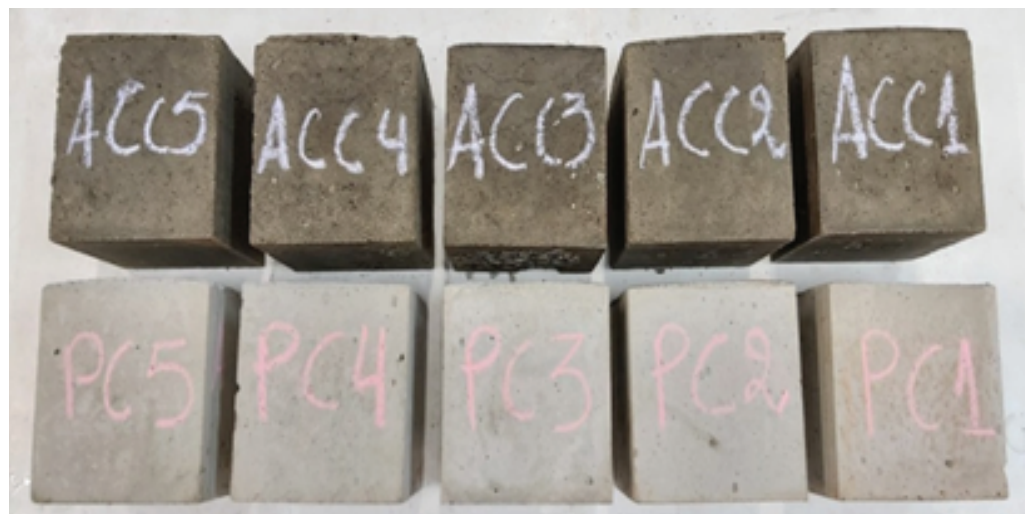

Figure 3: Samples of AAC and PCC

the prepared concrete mix in 3 equal layers by pouring the concrete: in which one is tamped with 25 strokes of the rounded end of the tamping rod in a uniform manner over the cross section of the mould. Afterwards, the mould is slowly raised vertically from the concrete and the slump is then measured as the difference between the height of the mould and that of height point of the specimen being tested.

\subsubsection{Compressive strength}

The compressive strength tests were performed on $3000 \mathrm{KN}$ electro-hydraulic mechanical testing machine "ADR Touch 3000 BS EN Compression Machine with Digital Readout and Self Centring Platens", in accordance with EN 196-1. Compressive strength data was obtained from testing a number of five of specimens of $25 \mathrm{~mm}$ cubic size.

\section{Results and Discussion}

This section is discussing the influence of L/S ratio on the workability and mechanical properties of $A A C$ and PCC.

The properties of concretes obtained using the methodology proposed show a good degree of workability without the presence of exudation and segregation phenomena with perfect aggregate distribution Fig.4.

\subsection{Workability (slump)}

There are several competing effects that affect the

workability namely: the particle size of the aggregate, temperature, chemical addition and liquid to solid ratio. 


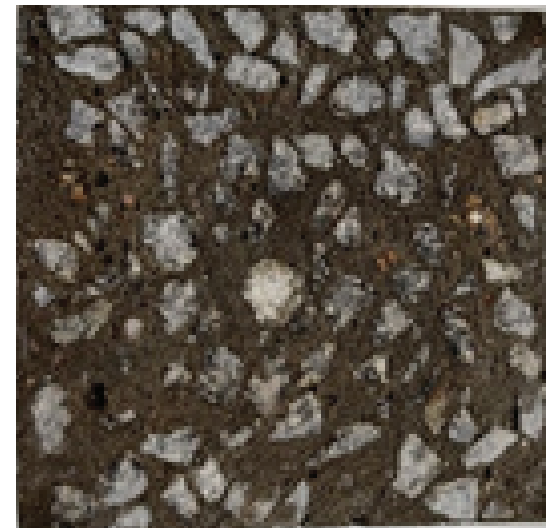

AAC

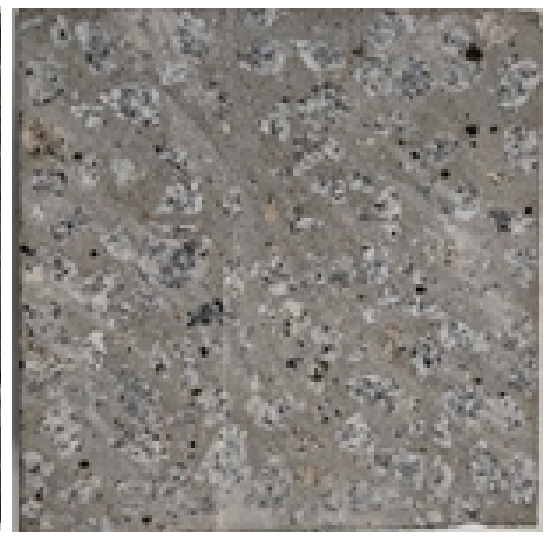

PCC

Figure 4: Distribution of aggregate in $A A C$ and PCC

Table. 5 presents the changes of the slump of AAC and PCC for different liquid/solid ratios $(0.50,0.52,0.54,0.56$ and 0.58$)$.

The value of the slump increases proportionally along with the liquid/solid ratio in AAC $(7 \mathrm{~mm}$ was measured for $0.5 \mathrm{~L} / \mathrm{S}$ (Fig.5) ratio and $16 \mathrm{~mm}$ for 0.58 and PCC (8.5 $\mathrm{mm}$ for $0.5 \mathrm{~L} / \mathrm{S}$ and $18 \mathrm{~mm}$ for 0.58). This can be explained by the solid content and the interparticle forces between particles. The solid content described by the empirical expression proposed by [12] as follows:

$$
E q: \mu=\mu_{0} \cdot\left(1-\left(\Phi / \Phi_{\max }\right)\right)^{n}
$$

Where $\mu_{0}$ is the solution viscosity, $\Phi$ is the actual solid volume fraction $\Phi_{\max }$ is the maximum solid volume fraction.

The concrete with a lower liquid phase which requires higher stress to break the interparticle forces and higher value of solid content (Eq (1)).

The table shows the difference between AAC and PCC slumps. This can be explained by the viscosity of the activator in AAC as in PCC the water is less viscous than the activator. Additionally, in PCC, the Portland cement contain gypsum as a regulator of setting time but in $A A C$, the precursor contains metakaolin and waste glass. For this reason, the slump in AAC was lower than in PCC.

\subsection{Compressive strength}

Water content has a significant effect on the mechanical performance of alkali-activated materials [13]. This is because water content has a direct influence on the total porosity of the alkali-activated matrix. Generally, higher water content will result in increased total porosity [14]. 
TABLE 5: Slump in AAC and PCC in mm.

\begin{tabular}{|l|c|c|}
\hline Ratio L/S & Slump of AAC $\mathbf{~ m m ~}$ & Slump of PCC $\mathbf{~ m m}$ \\
\hline $\mathbf{0 . 5 0}$ & 7 & 8.5 \\
\hline $\mathbf{0 . 5 2}$ & 8.5 & 10 \\
$\mathbf{0 . 5 4}$ & 11 & 13.5 \\
$\mathbf{0 . 5 6}$ & 13.5 & 15 \\
\hline $\mathbf{0 . 5 8}$ & 16 & 18 \\
\hline
\end{tabular}

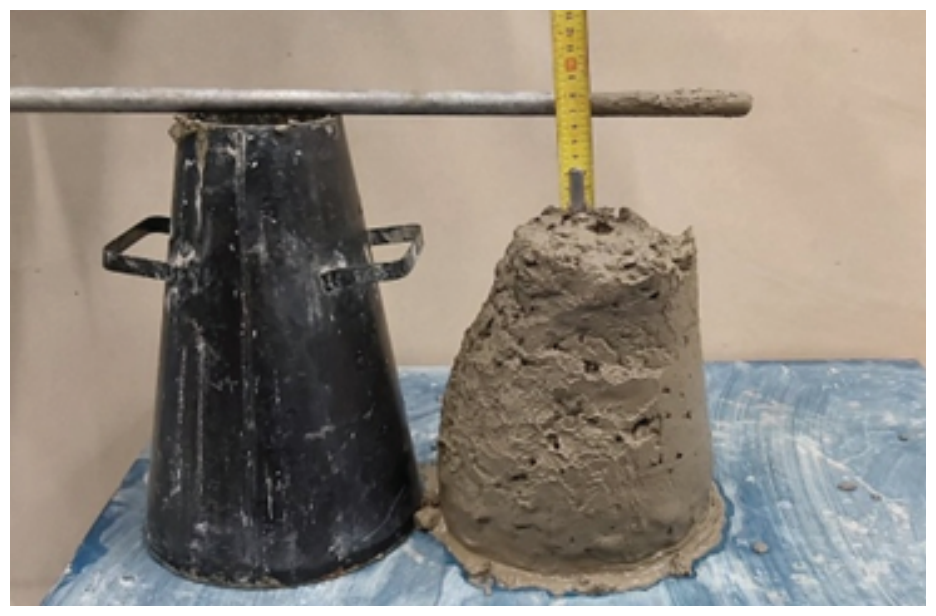

Figure 5: slump of $A C C$ with $0.5 \mathrm{~L} / \mathrm{S}$ ratio.

Fig. 6 presents the compressive strength results of $A A C$ and PCC measured at 7 days. Comparing the results obtained for the different mixtures, the compressive strength decreased with the increase of L/S ratios (a highest value in AAC was $15.9 \mathrm{MPa}$ with 0.5 L/S ratio but for PCC 17.9 MPa with the same L/S and for AAC a lower value was 10.5 $\mathrm{MPa}$ with $0.58 \mathrm{~L} / \mathrm{S}$ and for PCC was $11.4 \mathrm{MPa}$ ). This can be explained by the increasing of paste porosity and it also decreases because of the increasing of L/S influence on the cohesion between the particles of concrete.

\section{Conclusion}

This paper was a preliminary study of the rheological and mechanical properties of alkali-activated concrete based on tungsten mining waste mud. The main conclusions that can be drawn from this study are listed below:

- The possibility of obtaining an alternative concrete based tungsten mining waste mud by applying alkaline activation technology using conventional method for PCC. 


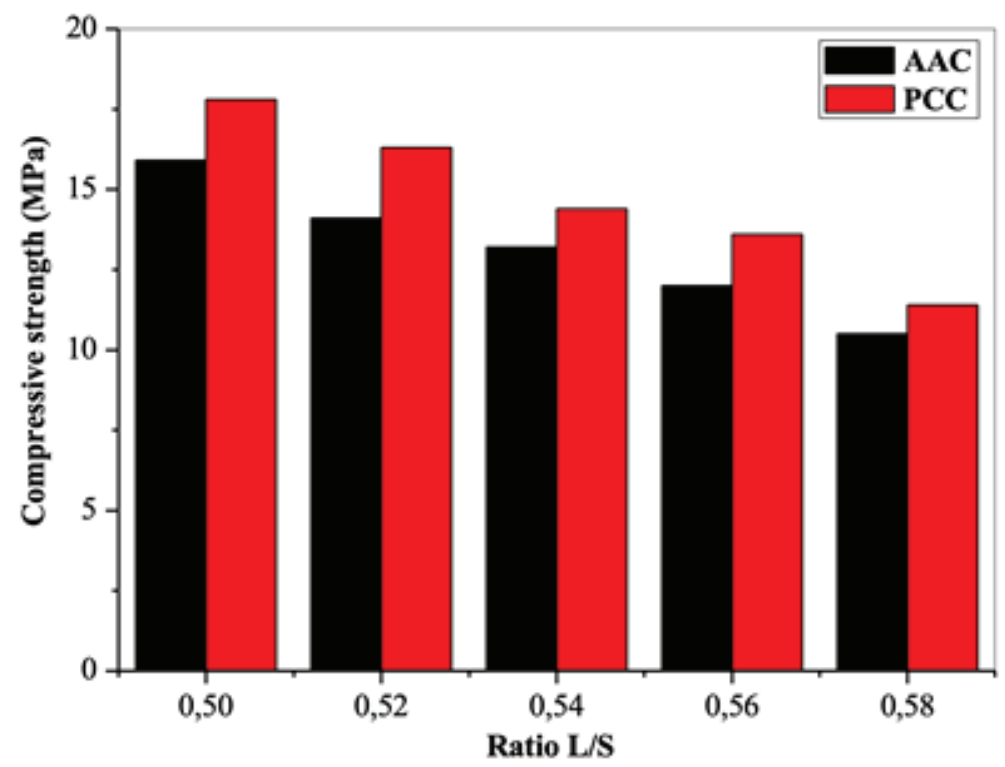

Figure 6: Compressive strength at 7 days as function with L/S ratio

- The ratio L/S affects the workability of alkali-activated concrete and Portland cement concrete and similar behavior was observed.

- The workability increases proportionally with the L/S ratio in ACC and PCC with more fluidity in PCC.

- The compressive strength at 7 days was affected by the L/S ratio (it decreases with the increasing of L/S ratio) in AAC and PCC with small difference between the two concretes.

- From this result on the workability and compressive strength, the use of this concrete depends on the rheological and mechanical performance to be obtained.

This work was partially financed by Portuguese national funds through FCT - Foundation for Science and Technology, IP, within the research unit C-MADE, Centre of Materials and Building Technologies (CIVE-Central Covilhã-4082), University of Beira Interior, Portugal.

\section{References}

[1] European Parliament, Council Directive 2013/59/Euratom of 5 December 2013 laying down basic safety standards for protection against the dangers arising from exposure to ionising radiation, and repealing Directives 89/618/Euratom, 90/641/Euratom, 96/29/Euratom, 97/43/Euratom a. Off J Eur Commun L13, (2014) 1-73. https://doi. org/doi:10.3000/19770677.L_2013.124.eng. 
[2] Bignozzi, M. C. et al. (2014). Room temperature alkali activation of fly ash: The effect of $\mathrm{Na} 2 \mathrm{O} / \mathrm{SiO} 2$ ratio. Construction and Building Materials, vol. 69, pp. 262-270.

[3] Hardjito R. B. V., Wallah S. E. and Sumajouw D.M.J. (2004). On the Development of Fly AshBased Geopolymer Concrete. ACl Materials Journal/November-December, vol. 101, No. 6, pp. 467-472.

[4] Castro-Gomes, J. P. et al. (2012). Potential for reuse of tungsten mining waste-rock in technical-artistic value added products. Journal of Cleaner Production, vol. 25, pp. $34-41$.

[5] A. Palomo, et al. (2014). A review on alkaline activation: new analytical perspectives. Materiales de Construcción, vol. 64, No. 315.

[6] Provis, J. L., Palomo, A. and Shi, C. (2015). Cement and Concrete Research Advances in understanding alkali-activated materials. Cement and Concrete Research, vol. 78, pp.110-125.

[7] Shi, C., Jiménez, A. F. and Palomo, A. (2011). Cement and Concrete Research New cements for the 21st century: The pursuit of an alternative to Portland cement. Cement and Concrete Research, vol. 41, pp.750-763.

[8] Chindaprasirt, P. (2007). Workability and strength of coarse high calcium fly ash geopolymer. Cement and Concrete Composites, vol. 29, No. 3, pp. 224-229. https: //doi.org/10.1016/j.cemconcomp.2006.11.002.

[9] Silva, A., et al. (2011). Cement \& Concrete Composites The effects of $\mathrm{Na}_{2} \mathrm{O} / \mathrm{SiO}_{2}$ molar ratio, curing temperature and age on compressive strength, morphology and microstructure of alkali-activated fly ash-based geopolymers. Cement and Concrete Composites, vol. 33, pp. 653-660.

[10] Mingyu, H., Xiaomin, Z. and Fumei, L. (2009). Cement \& Concrete Composites Alkaliactivated fly ash-based geopolymers with zeolite or bentonite as additives. Cement and Concrete Composites, vol. 31, pp. 762-768.

[11] Tattersall G. H. and Banfill, P. F. G. (1983). The rheology of fresh concrete. (Pitman Advanced Publishing Programme).

[12] Krieger, I. M. and Dougherty, T. J. (1959). A Mechanism for Non-Newtonian Flow in Suspensions of Rigid Spheres. Transactions of the Society of Rheology, vol. 3, pp. 137-152.

[13] Ahmari, S. and Zhang, L. (2012). Production of eco-friendly bricks from copper mine tailings through geopolymerization. Construction and Building Materials, vol. 29, pp. 323-331.

[14] Feng-qing, Z. (2009). Autoclaved brick from low-silicon tailings. Construction and Building Materials, vol. 23, pp. 538-541. 